\title{
Causes of visual impairment in people aged 75 years and older in Britain: an add-on study to the MRC Trial of Assessment and Management of Older People in the Community
}

\author{
J R Evans, A E Fletcher, R P L Wormald
}

Br J Ophthalmol 2004;88:365-370. doi: 10.1136/bjo.2003.019927

Background: Visual impairment and blindness are common in older people in Britain. It is important to know the causes of visual impairment to develop health service and research priorities. The authors aimed to identify the causes of visual impairment in people aged 75 years and older in Britain. Methods: In the MRC Trial of the Assessment and Management of Older People in the Community, trial nurses tested visual acuity in everyone aged 75 years and older in 53 general practices. For all visually impaired patients in 49 of the 53 medical practices, data regarding the cause of vision loss were extracted from the general practice medical notes. Additional follow up questionnaires were also sent to the hospital ophthalmologist to confirm the cause of vision loss. Visual impairment was defined as a binocular acuity of less than $6 / 18$.

Results: There were $1742(12.5 \%)$ people visually impaired in the 49 participating practices. Of these, $450(26 \%)$ achieved a pinhole visual acuity in either eye of $6 / 18$ or better. In these people, the principal reason for visual loss was considered to be refractive error. The cause of visual loss was available for $976(76 \%)$ of the remaining 1292 visually impaired people identified. The main cause of visual loss was age related macular degeneration (AMD); $52.9 \%$ (95\% confidence interval 49.2 to 56.5 ) of people had AMD as a main or contributory cause. This was followed by cataract (35.9\%), glaucoma (11.6\%), myopic degeneration $(4.2 \%)$, and diabetic eye disease (3.4\%).

Conclusions: A substantial proportion of visual impairment in our sample of older people in Britain can be attributed to remediable causes-refractive error and cataract. There is considerable potential for visual rehabilitation in this age group. For the large proportion with macular degeneration, low vision services will be important.

$\mathrm{V}$ sual impairment and blindness are common in older people in Britain. ${ }^{1-4}$ It is important to know the causes of visual impairment to develop health service and research priorities. There is little information on the cause of visual impairment in people aged 75 years or more in Britain and particularly limited data for people aged 90 years and older.

As part of the MRC Trial of the Assessment and Management of Older People in the Community, a visual acuity screening test was conducted by trained nurses in a representative group of 14600 people aged 75 years and older recruited from general practice in Britain. The prevalence of visual impairment in this population has previously been reported. ${ }^{4}$ This paper presents the causes of visual impairment.

\section{METHODS}

The study reported here is an add-on study to the MRC Trial of the Assessment and Management of Older People in the Community. Details of the design of the MRC trial and the measurement of visual acuity and prevalence of visual impairment have been reported elsewhere. ${ }^{45}$ As part of the trial, 53 general practices were randomly allocated to deliver a detailed health assessment to people aged 75 years and older on the practice list. This detailed health assessment included measurement of visual acuity at 3 metres with a Glasgow acuity chart. ${ }^{6}$ Presenting binocular vision was measured first, followed by vision in the right and left eyes. All vision measurements were conducted with usual spectacle correction. People with $\log$ MAR visual acuity of 0.5 or more in either eye (equivalent to less than 6/18 Snellen acuity) were retested with a pinhole occluder. If vision did not improve to less than 0.5 , and the cause of visual loss had not previously been investigated, the person was referred to an ophthalmologist. If vision improved to less than 0.5 , the patient was advised to see an optometrist.

All 53 practices taking part in the "universal" arm of the trial were approached to take part in the causes of visual impairment study (fig 1). Practices in the "targeted" arm of the trial were not included in the study because visual acuity tests in these practices were only done on people specifically selected to have high levels of morbidity and therefore their visual impairment levels (and other factors) were not representative of the background population.

For those practices $(n=49)$ that agreed to take part the following procedures took place. Firstly, a list of visually impaired people was compiled. For the purposes of this study, visual impairment was defined as presenting binocular acuity of less than 6/18. People who achieved a pinhole acuity in either eye of $6 / 18$ or better were considered to be visually impaired because of refractive error.

JE sent each study nurse a list of people with visual impairment for their practice. The study nurse abstracted diagnostic information from the general practitioner notes derived from correspondence between the hospital ophthalmologist and general practitioner. Information was extracted on dates of patient visits and results of the clinical examinations including visual acuity, diagnosis, and treatment. The forms were returned to JE who coded them twice. A maximum of three diagnoses were recorded. The main cause of visual impairment was taken to be the cause of visual loss in the eye that lost vision most recently as this was the cause of visual loss that was considered to have made the person visually impaired. If the main cause of visual loss was 


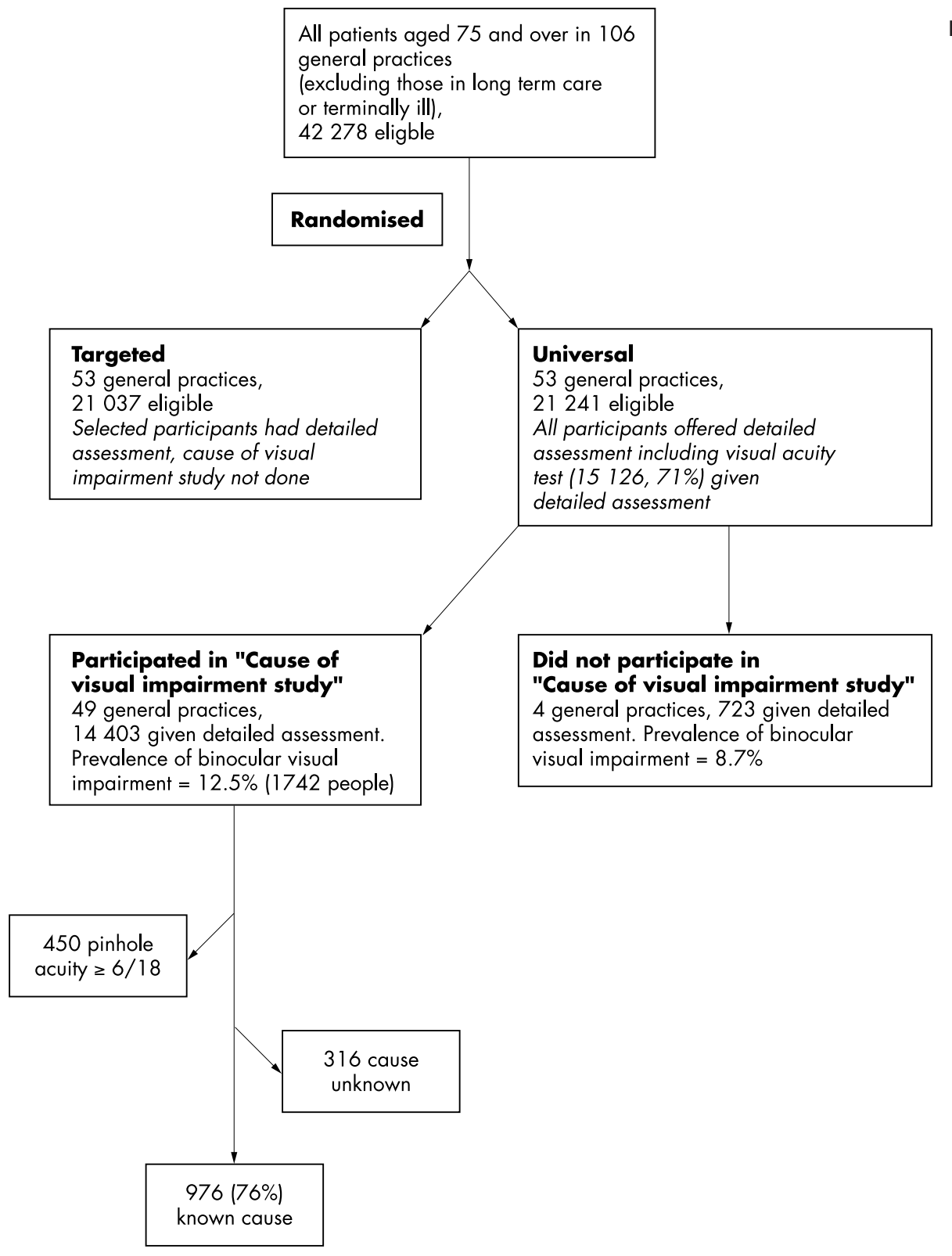

Figure 1 Study profile.

75 and over in 106

(excluding those in long term care

or terminally ill),

42278 eligble

53 general practices

21037 eligible

assessment, cause of visual

All participants offered detailed

visual acuity

est (15 126, $71 \%$ ) given

detailed assessment

not clear then the two main diagnoses were each assumed to contribute to the visual loss.

In order to validate the causes of visual loss obtained from coding the diagnostic information obtained from the general practitioner notes, a one page questionnaire was sent to the hospital ophthalmologist who had last seen the patient. This questionnaire was in the form of a check list by eye that covered: age related macular degeneration (exudative, geographic atrophy), cataract (age related, congenital, other), glaucoma (primary open angle, primary closed angle, other), diabetes (diabetic retinopathy, other), myopic degeneration, other (specify). The ophthalmologist was asked to rank, if possible, any conditions ticked in order of their contribution to cause of visual loss. In addition, they recorded which eye lost vision last and visual acuity at last examination.

As this was additional data collection to that originally in the protocol for the MRC Trial we obtained approval from all the relevant local research ethics committees.

All analyses were done using Stata version 7.0 (Stata Corporation, College Station, TX, USA). All analyses took account of the cluster sampling in the estimation of confidence intervals and $\mathrm{p}$ values.

Measurements of visual acuity were made between 1995 and 1998; data collection on cause of visual loss took place between 1996 and 2000 .

\section{RESULTS}

The 49 practices taking part in the cause of visual impairment study had a similar age (mean age $81.3 v 81.6, \mathrm{p}=0.119$ ) and sex (percentage male $38 \%$ v 37\%, p=0.842) distribution compared to the four practices that declined to take part. Participating practices were a little larger (294 $v$ 181, $\mathrm{p}=0.183)$ and had a slightly higher level of visual impairment (prevalence $12.5 \% \vee 8.7 \%, \mathrm{p}=0.136$ ); however, these differences were not statistically significant.

In these 49 practices, there were 1742 (12.5\%) people who had a binocular acuity of less than 6/18. Of these $450(26 \%)$ achieved a pinhole acuity of better than or equal to $6 / 18$ in the better eye. In these people the principal cause of visual impairment was considered to be refractive error. Cause of visual loss was available for 976 (76\%) of the remaining 1292 
visually impaired people. There were 316 people for whom we could not identify the cause of visual loss. In 43\% (137) of these missing cases the practice nurse was unable to locate the medical notes, either because the patient had moved practice or died, or the notes were lost. In a further $42 \%$ (134) of cases, the practice nurse was able to obtain the medical notes but there was no record of the patient having an eye examination. In 5\% (15) it was not clear from the notes what the cause of visual loss was.

People for whom data on the cause of visual loss were available were marginally younger (mean age $84.7 v 85.5$, $\mathrm{p}=0.036$ ) and had a worse visual acuity compared to those for whom data were not available; $25.5 \%$ had a visual acuity of less than $3 / 60$ compared to $12.2 \%$ of people for whom cause of visual loss was not available $(\mathrm{p}<0.001)$. There were no sex differences (percentage male $28 \% \vee 28 \%$, $\mathrm{p}=0.957$ )

A total of $470(48 \%)$ forms were completed by consultant ophthalmologists. Of these, three people appeared to have a mistaken identity and were excluded, leaving a total of 467 forms.

The main difference between the two sources of data was that the hospital ophthalmologist recorded fewer potential causes of visual loss. In $46 \%$ of cases only one condition was recorded. In the review of the general practice medical records only one condition was recorded in $32 \%$ of cases. In addition to recording fewer potential causes of visual loss, the hospital consultant was more likely to attribute a main cause in cases where several conditions co-existed. S/he attributed a main cause in $86 \%$ of cases where several conditions coexisted, in contrast with review of the general practice medical notes where a main cause was attributed in $65 \%$ of cases with multiple conditions. In 335/467 cases (72\%), both the medical record review and hospital consultant questionnaire attributed a main cause of visual loss. In 295 (88\%) of these 335 cases, the two sources of data agreed as to what was the main cause of visual loss (kappa $=0.81$ ).

Table 1 shows the main causes of visual impairment. The data are drawn from the hospital questionnaire, where available, and from the coding of general practice notes otherwise. As $16 \%$ of people had more than one cause of visual loss the total adds up to more than $100 \%$. The table shows the causes of visual loss as a percentage of three different denominators: (i) people with binocular visual impairment, (ii) people with binocular visual impairment excluding people in whom the principal cause of visual loss was assumed to be refractive error, and (iii) everyone aged 75 years and older.

The main cause of visual loss was AMD, followed by (refractive error), cataract, glaucoma, myopic degeneration, diabetic eye disease, and vascular occlusions. If all visually impaired people are included in the denominator, the proportion of people with AMD as a main or contributory cause of visual loss is estimated at $36.2 \%$ (95\% CI 32.9 to 39.5). If people with refractive error are excluded, the proportion affected by AMD increases to $52.9 \%$ (95\% CI 49.2 to 56.5 ); $3.7 \%$ (95\% CI 3.2 to 4.2 ) of the entire cohort of people aged 75 years and older had AMD causing visual impairment.

The most commonly occurring "other" cause of visual loss was corneal opacity which affected 17 people. In seven of these people this was considered the main cause of visual loss, in the rest it was a contributory cause with AMD (one person), cataract (eight people), and retinal detachment (one person); 10 of these 17 had Fuchs' endothelial dystrophy; 15 had some form of retinal degeneration. There were three cases of retinitis pigmentosa and eight macular holes. Twelve people were visually impaired because of disease of the visual cortex or optic pathways. In the majority of cases (seven) this was optic nerve disease. Seven people had retinal detachments. In most of these cases this was considered to be the main cause of visual loss. There were a small number of people (five) who had visual symptoms such as diplopia or who had systemic disease causing tremor which affected their vision. Herpes zoster, uveitis, and trauma accounted for a further six cases.

In all, $350(25 \%)$ visually impaired people had cataract as the main or contributory cause of visual loss. In the majority of cases $(281,80 \%)$ there was record in the medical notes before the MRC trial detailed examination that the person had a cataract. Thirty six people were on the waiting list and eight people were in the process of being referred; 50 had already had a cataract operation in one or both eyes but still failed the visual acuity test at the detailed examination. Three of these took part in the MRC trial shortly after their cataract operation and their vision probably had not settled down, a further 14 had record of surgical complications, high astigmatism, or capsular opacification that could account for the visual loss. In most cases, however, there was no obvious reason why the person should not have achieved good vision after cataract surgery.

In 187 of the 281 people for whom cataract had been identified before the MRC trial an operation had not been performed; 28 of these people had refused the operation and for 56 there was record that a decision had been taken not to do the operation for health reasons. In the remaining 103, the record of ophthalmic examinations before the MRC trial had indicated that the lens opacity had been mild. In the majority of these cases (62) no further follow up took place. In 31, they were referred again within 1 year of the MRC trial, and in 10 after one year after the MRC trial examination.

Table 2 shows the causes of visual loss by age and sex. In both men and women refractive error was the most

Table 1 Causes of visual impairment (binocular visual acuity $<6 / 18$ )

\begin{tabular}{|c|c|c|c|c|c|c|c|}
\hline \multirow[b]{2}{*}{ Cause } & \multirow{2}{*}{$\begin{array}{l}\text { No with condition } \\
\text { main/contributory } \\
\text { cause }\end{array}$} & \multicolumn{2}{|c|}{$\begin{array}{l}\text { Binocular visual impairment } \\
\text { ( } n=1426)\end{array}$} & \multicolumn{2}{|c|}{$\begin{array}{l}\text { Binocular visual impairment, } \\
\text { excluding refractive error } \\
(\mathbf{n = 9 7 6 )}\end{array}$} & \multicolumn{2}{|c|}{$\begin{array}{l}\text { Everyone aged } 75 \text { years and } \\
\text { older }(n=13900)\end{array}$} \\
\hline & & $\%$ & $95 \% \mathrm{Cl}$ & $\%$ & $95 \% \mathrm{Cl}$ & $\%$ & $95 \% \mathrm{Cl}$ \\
\hline Refractive error & 450 & 31.6 & 28.3 to 34.8 & - & - & 3.2 & 2.6 to 3.8 \\
\hline AMD & 516 & 36.2 & 32.9 to 39.5 & 52.9 & 49.2 to 56.5 & 3.7 & 3.2 to 4.2 \\
\hline Cataract & 350 & 24.5 & 21.8 to 27.4 & 35.9 & 31.7 to 40.1 & 2.5 & 2.0 to 3.0 \\
\hline Glaucoma & 113 & 7.9 & 6.2 to 9.6 & 11.6 & 9.1 to 14.0 & 0.8 & 0.6 to 1.0 \\
\hline Diabetic eye disease & 33 & 2.3 & 1.5 to 3.1 & 3.4 & 2.2 to 4.6 & 0.2 & 0.15 to 0.32 \\
\hline Vascular occlusions & 9 & 0.6 & 0.1 to 1.1 & 0.9 & 0.2 to 1.6 & 0.06 & 0.01 to 0.11 \\
\hline Myopic degeneration & 41 & 2.9 & 1.9 to 3.8 & 4.2 & 2.8 to 5.6 & 0.3 & 0.2 to 0.4 \\
\hline Other & 67 & 4.7 & 3.7 to 5.7 & 6.9 & 5.5 to 8.2 & 0.5 & 0.4 to 0.6 \\
\hline
\end{tabular}

Refractive error $=$ people with pinhole corrected vision in right or left eye of $6 / 18$ or better; no cause was established in 316 people; total is more than $100 \%$ as $16 \%$ of people had more than one cause of visual loss.

$\mathrm{AMD}$, age related macular degeneration. 
Table 2 Causes of visual impairment by age and sex

\begin{tabular}{|c|c|c|c|c|c|c|}
\hline & \multirow{2}{*}{$\begin{array}{l}\text { No in } \\
\text { group }\end{array}$} & \multicolumn{5}{|l|}{$\%$ attributed to: } \\
\hline & & Refractive error & AMD & Cataract & Glaucoma & Diabetes \\
\hline \multicolumn{7}{|l|}{ Men } \\
\hline $75-79$ & 113 & 40.7 & 23.0 & 17.7 & 9.7 & 8.0 \\
\hline $80-84$ & 141 & 32.6 & 33.3 & 19.2 & 12.1 & 5.0 \\
\hline $85-89$ & 120 & 33.3 & 37.5 & 28.3 & 10.8 & 0.8 \\
\hline $\begin{array}{l}90+ \\
\text { Women }\end{array}$ & 36 & 22.2 & 55.6 & 33.3 & 2.8 & 0 \\
\hline $75-79$ & 234 & 42.3 & 20.5 & 24.4 & 4.7 & 1.7 \\
\hline $80-84$ & 309 & 34.0 & 36.3 & 22.3 & 7.8 & 1.6 \\
\hline $85-89$ & 311 & 23.8 & 42.1 & 29.6 & 7.7 & 1.9 \\
\hline $90+$ & 162 & 19.8 & 53.7 & 24.1 & 7.4 & 0.6 \\
\hline
\end{tabular}

important cause of visual loss at ages 75-79. In men, AMD was the most important cause of visual loss at all ages. In women, at the younger age groups, 75-79, cataract was the most important cause of visual loss. With increasing age, AMD became the predominant cause.

Table 3 shows the causes of visual loss by binocular visual acuity score. This shows that refractive error and cataract predominate as causes of low vision (binocular acuity $<6 / 18$ to 3/60) in the younger age groups, but AMD becomes a more important cause of low vision at older ages. AMD is the main cause of blindness; at ages 90 and older, $88.4 \%$ of people with vision of less than $3 / 60$ (blind) were visually impaired due to AMD.

\section{DISCUSSION}

This study presents the causes of vision loss in a large sample of visually impaired people aged 75 years and older drawn from 49 general practices selected to be representative of the population of Britain. Previous studies into the causes of visual impairment in this age group in Britain either have not been representative of the general population ${ }^{7}$ or have had a small sample size. ${ }^{12}$ The MRC Trial of the Assessment and Management of Older People in the Community provided the opportunity to identify a large group of visually impaired older people and ascertain the cause of visual loss.

Refractive error was a major cause of visual loss with one in four people visually impaired because of refractive error. It is likely that this is an underestimate of the impact of refractive error. Because of the size and geographical distribution of the MRC trial we were only able to use a pinhole occluder to adjust for refractive error. Although it is known that this compares less favourably with subjective refraction, it has been assessed to be adequate in validation studies. ${ }^{8}$ However, use of the pinhole was not straightforward in this elderly population and only $62 \%$ of people with visual acuity less than $6 / 18$ in either eye completed a pinhole test satisfactorily. ${ }^{4}$ The importance of refractive error as a potential cause of visual impairment in older people has been observed before. For example, a study of nursing home residents in Baltimore judged that $20 \%$ of functional blindness and $37 \%$ of visual impairment could be treated with adequate refractive correction. ${ }^{9}$ In the Blue Mountains Eye Study, two in every three cases of visual impairment were judged to be due to uncorrected refractive error; however, visual impairment was defined using the lower threshold of $6 / 12 .^{10}$

The size and national representativeness of the study improve the precision and generalisability of the results. A limitation was that the assessment of the cause of visual loss relied upon abstraction of the correspondence between the hospital eye service and general practitioner. It would have been prohibitively expensive to coordinate ophthalmic examinations on all participants in the study. We were able to cross check the diagnosis with the hospital consultant for nearly $50 \%$ of the sample. Information from the hospital and general practice agreed well. We believe that, for the simple categories of cause presented in this paper, this method of assessment has worked well.

AMD was the most important cause of visual loss in people aged 75 years and older, being either the major or an important contributory cause in $36 \%$ of people who were binocularly visually impaired. It is more usual in eye surveys to consider the impact of AMD as a cause of visual loss after excluding people who are visually impaired because of refractive error from the denominator. In this study population, 53\% of people who were binocularly visually impaired, but who did not achieve a pinhole acuity in either eye of 6/18 or better, had AMD as a main or contributory cause of visual loss.

There was a strong age effect, whereby people aged 90 years and older were proportionately more affected by AMD. This age effect has been seen in other studies. ${ }^{11}$ It is

Table 3 Causes of low vision and blindness

\begin{tabular}{|c|c|c|c|c|c|c|}
\hline & \multirow{2}{*}{$\begin{array}{l}\text { No in } \\
\text { group }\end{array}$} & \multicolumn{5}{|l|}{$\%$ attributed to: } \\
\hline & & Refractive error & AMD & Cataract & Glaucoma & Diabetes \\
\hline \multicolumn{7}{|c|}{ Low vision $(<6 / 18-3 / 60)$} \\
\hline 75-79 & 312 & 46.5 & 18.0 & 23.7 & 5.1 & 2.9 \\
\hline $80-84$ & 360 & 41.7 & 26.7 & 25.3 & 8.1 & 2.5 \\
\hline $85-89$ & 349 & 32.7 & 33.5 & 32.3 & 7.5 & 2.0 \\
\hline $90+$ & 155 & 25.8 & 44.5 & 30.3 & 4.5 & 0.7 \\
\hline \multicolumn{7}{|c|}{ Blindness $(<3 / 60)$} \\
\hline 75-79 & 35 & 0 & 51.4 & 8.6 & 17.1 & 11.4 \\
\hline $80-84$ & 90 & 1.1 & 70.0 & 5.6 & 13.3 & 3.3 \\
\hline $85-89$ & 82 & 0 & 72.0 & 15.9 & 13.4 & 0 \\
\hline $90+$ & 43 & 0 & 88.4 & 9.3 & 14.0 & 0 \\
\hline
\end{tabular}


Table 4 Comparison with other population based studies on the causes of visual loss

\begin{tabular}{|c|c|c|c|c|c|c|c|}
\hline \multirow[b]{2}{*}{ Study } & \multirow[b]{2}{*}{ Age } & \multirow{2}{*}{$\begin{array}{l}\text { Definition of visual } \\
\text { impairment }\end{array}$} & \multirow{2}{*}{$\begin{array}{l}\text { Not visually } \\
\text { impaired }\end{array}$} & \multicolumn{4}{|c|}{$\%$ attributed to: } \\
\hline & & & & AMD & Cataract & Glaucoma & Diabetes \\
\hline \multicolumn{8}{|l|}{ Low vision } \\
\hline MRC trial & $75+$ & $<6 / 18-3 / 60$ & 727 & 47 & 45 & 11 & 4 \\
\hline Baltimore Eye Study & $65+$ & $<6 / 12->6 / 60$ & 134 & 25 & 44 & 3 & 0 \\
\hline SEE & $40+$ & $<6 / 18->=6 / 60$ & 31 & 23 & 10 & 16 & 10 \\
\hline Melbourne VIP & $>65$ & $<6 / 18->6 / 60$ & 21 & 38 & 33 & 10 & 5 \\
\hline $\begin{array}{l}\text { Blue Mountains Eye } \\
\text { Study }\end{array}$ & $65-84$ & $<6 / 12->6 / 60$ & 50 & 32 & 42 & 2 & 8 \\
\hline Rotterdam Study* & $75+$ & $<6 / 18-3 / 60$ & 170 & 28 & 57 & 2 & 0 \\
\hline $\begin{array}{l}\text { Blue Mountains Eye } \\
\text { Study } \\
\text { Blindness }\end{array}$ & $65-84$ & $<=6 / 60$ & 10 & 70 & 0 & 10 & 0 \\
\hline MRC trial & $75+$ & $<3 / 60$ & 249 & 71 & 10 & 14 & 3 \\
\hline Baltimore Eye Study & $65+$ & $<=6 / 60$ & 42 & 38 & 17 & 14 & 2 \\
\hline Beaver Dam Eye Study & $40+$ & $<=6 / 60$ & 21 & 57 & 5 & 0 & 10 \\
\hline SEE & $>65$ & $<6 / 60$ & 15 & 40 & 13 & 33 & 0 \\
\hline Melbourne VIP & $40+$ & $<=6 / 60$ & 24 & 88 & 4 & 0 & 0 \\
\hline $\begin{array}{l}\text { Blue Mountains Eye } \\
\text { Study }\end{array}$ & $65-84$ & $<=6 / 60$ & 10 & 70 & 0 & 10 & 0 \\
\hline Rotterdam Study* & $75+$ & $<3 / 60$ & 50 & 70 & 8 & 6 & 0 \\
\hline
\end{tabular}

also interesting to note that women were more affected by cataract at younger ages. We also found a strong relation with visual acuity, cataract causing more moderate visual impairment whereas AMD resulted in poorer vision. This effect was independent of age. Refractive error was an important cause of low vision in men and women at younger age groups.

Cataract was a relatively frequent cause of visual impairment. One in three of the people who did not achieve vision of better than 6/18 with a pinhole occluder (or who could not use a pinhole occluder) and for whom we could identify a cause of visual loss, apparently were visually impaired because of cataract. Only a minority of these were newly identified with cataract at the time of the MRC trial or afterwards. Some people had had an operation before the MRC trial but did not achieve good vision at the MRC trial examination. Although cataract surgery is a safe and effective operation, not everyone achieves good functional vision afterwards. ${ }^{12}$ Further intervention to correct astigmatism or deal with capsular opacification, for example, may be of benefit. The majority of people visually impaired as a result of cataract at the time of the MRC trial examination had been identified with cataract before the trial. Some of these had refused surgery, or had other reasons not to have surgery. In a substantial proportion the cataract had not been sufficiently disabling to require cataract surgery at that time. Regular follow up of these people may well have resulted in more timely cataract surgery and prevention of visual impairment.

Table 4 compares these results with other published studies from similar populations in North America, Australia, and Europe. The number of people with low vision $(n=727)$ and blindness $(n=249)$ with cause of visual loss identified in the MRC trial was substantially larger than for other comparable studies (range 10-50 blind people and 21-170 people with low vision). The results compare well with other studies and show that the pattern of cause of visual loss differs according to the level of visual loss. AMD is proportionately a more important cause of blindness than of low vision; conversely cataract is generally, although not always, found to be a more important cause of low vision than AMD.

People in institutions were not included in our sample. Approximately $10 \%$ of the population aged 75 years and above in the United Kingdom are in nursing homes. It is unlikely that excluding the nursing home population will substantially affect estimates of the prevalence of visual impairment. Previous studies of the non-community dwelling older people have demonstrated that cataract and AMD are important causes of visual impairment in this population. ${ }^{9}{ }^{13} 14$

In conclusion, a substantial proportion of visual impairment in our sample of older people in Britain was caused by refractive error and cataract. These conditions have safe and effective interventions. The challenge is how to deliver these interventions in a timely fashion in this age group. There is little in the way of preventive or curative intervention for AMD; low vision services will be important, particularly in the very elderly.

The population of the United Kingdom is ageing rapidly. By 2040, the numbers of people aged 75 years and above are projected to increase by $90 \%$ and the numbers of people aged 90 years and above by 160\% (www.gad.gov.uk/population/ accessed December 2002). Age related diseases such as cataract and AMD will assume increasing importance in the public health of the nation.

\section{ACKNOWLEDGEMENTS}

We would like to thank the following people: Professor Chris Bulpitt, Dr Dee Jones, and Dr Alistair Tulloch, co-investigators on the MRC Trial of Assessment and Management of Older People; the nurses, GPs, the other staff and the patients in the participating practices: the consultant ophthalmologists who completed questionnaires; the MRC General Practice Research Framework Coordinating centre, particularly Madge Vickers, Jeannett Martin, and Nicky Fasey; the research team for the MRC Trial of Assessment and Management of Older People in the Community—Elizabeth Breeze, Edmond Ng, Gill Price, Liam Smeeth, Susan Stirling, Rakhi Kabiwala, and Janbibi Mazar at London School of Hygiene and Tropical Medicine, Maria Nunes and Ruth Peters at Imperial College; Amina Latif and Elaine Stringer, University of Wales College of Medicine; the Trial Steering Committee, Professor J Grimley Evans (chair), Professor Andy Haines, Professor Carol Brayne, and Professor Karen Luker.

\section{CONTRIBUTORS}

All authors were involved in the design, interpretation and write up of the study. JE did the data collection and analysis and acts as guarantor of the paper.

\section{Authors' affiliations}

J R Evans, R P L Wormald, Department of Epidemiology and International Eye Health, Institute of Ophthalmology, London, UK 
A E Fletcher, Centre for Ageing and Public Health, London School of Hygiene and Tropical Medicine, London, UK

Funding: The MRC Trial of the Assessment and Management of Older People in the Community was funded by the UK Medical Research Council, the Department of Health, and the Scottish Office. Collection of data on causes of visual impairment was funded by the Gift of Thomas Pocklington.

Conflict of interest: None.

Correspondence to: Ms Jennifer Evans, Department of Epidemiology and International Eye Health, Institute of Ophthalmology, London, UK; jennifer.evans@|shtm.ac.uk

Accepted for publication 28 May 2003

\section{REFERENCES}

1 Wormald RP, Wright LA, Courtney $P$, et al. Visual problems in the elderly population and implications for services. BMJ 1992;304:1226-9.

2 Reidy A, Minassian DC, Vafidis G, et al. Prevalence of serious eye disease and visual impairment in a north London population: population based, cross sectional study. BMJ 1998;316:1643-6.

3 Van der Pols JC, Bates CJ, McGraw PV, et al. Visual acuity measurements in a national sample of British elderly people. Br J Ophthalmol 2000:84:165-70.

4 Evans JR, Fletcher AE, Wormald RPL, et al. Prevalence of visual impairment in people aged 75 years and older in Britain: results from the MRC trial of assessment and management of older people in the community. Br J Ophthalmol 2002;86:795-800.

5 Fletcher AE, Jones DA, Bulpitt CJ, et al. The MRC Trial of assessment and management of older people in the community: objectives, design and interventions [ISRCTN23494848]. BMC Health Services Research 2002;2:21.

6 McGraw PV, Winn B. Glasgow acuity cards: a new test for the measurement of letter acuity in children. Ophthalmol Physiol Opt 1993;13:400-4.

7 Evans JR. Causes of blindness and partial sight in England and Wales 1990-1991. Studies on Medical and Population Subjects 57. London: HMSO, 1995.

8 Ederer F, Krueger DE, Mowery RL, et al. Lessons from the Visual Acuity Impairment Survey Pilot Study. Am J Publ Health 1986;76:160-5.

9 Tielsch JM, Javitt JC, Coleman A, et al. The prevalence of blindness and visual impairment among nursing home residents in Baltimore. N Engl J Med 1995;332:1205-9.

10 Foran S, Rose K, Wang JJ, et al. Correctable visual impairment in an older population: the Blue Mountains Eye Study. Am J Ophthalmol 2002;134:712-9.

11 Klaver CC, Wolfs RC, Vingerling JR, et al. Age-specific prevalence and causes of blindness and visual impairment in an older population: the Rotterdam Study. Arch Ophthalmol 1998;116:653-8.

12 Desai $\mathbf{P}$, Minassian DC, Reidy A. National cataract surgery survey 1997-8: a report of the results of the clinical outcomes. $\mathrm{Br} J$ Ophthalmol 1999;83:1336-40.

13 Mitchell P, Hayes P, Wang JJ. Visual impairment in nursing home residents: the Blue Mountains Eye Study. Med J Aust 1997; 166:73-6.

14 VanNewkirk MR, Weih L, McCarty CA, et al. Visual impairment and eye diseases in elderly institutionalized Australians. Ophthalmology 2000;107:2203-8. 